\title{
Periodic Signals of the Milky Way Concealed in Terrestrial Sedimentary Basin Fills and in Planetary Magmatism?
}

\author{
Heinz-Jürgen Brink* \\ Institute of Geophysics, University of Hamburg, Hamburg, Germany \\ Email: 0511814674-0001@t-online.de
}

Received 29 June 2015; accepted 4 August 2015; published 7 August 2015

Copyright (C) 2015 by author and Scientific Research Publishing Inc.

This work is licensed under the Creative Commons Attribution International License (CC BY). http://creativecommons.org/licenses/by/4.0/

(c) () D Den Access

\begin{abstract}
Long periodic geodynamic processes with durations between 150 and 600 Million years appear to be in phase with similar galactic cycles, caused by the path of the solar system through the spiral arms of the Milky Way. This path is assumed by some authors to cause climate change due to cosmic ray fluctuations, affecting the cloud formation and the related albedo of the Earth, which periodically lead to glaciations every $150 \mathrm{Ma}$. With the glaciations, the sea level fluctuates accordingly. Subsequently, the varying sizes of shallow seas are causing periodic changes of the Moon's tidal dissipation, which affects presumably other geodynamic processes on the Earth. The Moon may therefore synchronize directly or indirectly long periodic Phanerozoic cycles (sea level, orogeny, magmatism, sedimentation, etc.) with the Milky Way. As sea level fluctuations, orogeny, sedimentation and magmatism can be described as members of a geodynamic feedback system; no apparent reasons appear to be required to assign a cause of the cyclicity to agents outside of the galactic-climatically synchronized Earth-Moon system. However, recent observations of young volcanism on the near Earth terrestrial planets may require a new understanding. Magmatic/volcanic episodes on Venus, Mars and Mercury as well as on the Earth's Moon are apparently contemporaneous thermal events accompanying increased magmatic/volcanic activities on the Earth, following a $\mathbf{3 0 0}$ myr cycle. Therefore, a collateral galactic thermal source within the Milky Way appears to be needed that only affects the interior of the planets without any recognizable direct effect on life and geology on the Earth. The search for such a source may lead to astrophysical questions, related to a spiral arm affected distribution of dark energy, dark matter or even specific neutrino sources. However, all possible astrophysical answers are outside of the author's competence.
\end{abstract}

\section{Keywords}

Milky Way, Spiral Arms, Planets, Sea Level, Magmatism, Climate Change

${ }^{*}$ Contact address: Hindenburgstrasse 39, 30175 Hannover, Germany. 


\section{Introduction}

In the analysis of the Earth's history, including exploration activities for hydrocarbons, the investigation of geodynamic periodicities plays a crucial role (e.g. [1]-[19]). This includes obvious long-periodic processes like the repeated appearance of super-continents approximately every 600 million years [1] [20], and sea level-fluctuations (Figure 1), plate-tectonics and its magmatic and mountain-forming periods and also magnetic-field-variations, showing amplitude-maxima approximately every 300 million years with a very different phase-behavior.

Climate-fluctuations approximately every 150 million years [21]-[23] add a further dominant period (Figure 2), leaving behind anomalous sedimentary fills of evaporates [1] [24] and oolithiclimestones [25] at least during the last $400 \mathrm{Ma}$ (Figure 3).

During the Upper Jurassic, archived global sedimentation anomalies with the distribution of possible glacial sediments which hypothesize a temporary glaciation of areas near the poles also in the mainly warm Mesozoic [26], evaporates [27], oil source rocks and natural gas source rocks (after [28]) prove the periodic climatic control. Additionally, many further geological, geochemical and biological processes occurring over shorter periods are also very important [29]-[35].

The 150 million year periodicity of the climate cycle can be derived from two 300 million years' cycles that are phase-shifted by approximately $90^{\circ}$ against each other, if both have a crucial influence on the climate. That is certainly the case for the global sea level fluctuations and the periodic expansion of continental mountain ranges, showing roughly such a phase-shift [36]. Very short-periodic processes that, for example, reappear in the sedimentation-pattern and in the appearance of maxima of ice age glacier expansions, are caused by planetary rotation parameters of the Earth around the Sun (Milankovic-cycles) (e.g. [37]-[41]). The short-periodic appearance of several ice ages in Europe and America during the last few hundred thousand years is used as an approximation for climate-fluctuations [42]. Also in a long-periodic view, climate-fluctuations on the Earth went along with intensive glaciations [43] [44]. The most-extreme glaciations in this view are the probable complete multiple freezing episodes of the entire Earth into "Snowballs" approximately 750 - 600 million years ago [45][48], plus/minus synchronously with the merging of most continents into the super-continent Rodinia and its following break-up [49] [50]. In that time, the continent-fragments of the Earth were covered with icecaps that were up to four kilometers thick. These icecaps temporarily contained volumes of up to 350 million $\mathrm{km}^{3}$ of frozen water [51] [52]. The sea was also most likely concealed by a mighty ice layer approximately one kilometer thick [53]. The water bound on the continents as ice must have led to a global drop of the sea level by several hundred meters. At this time the sea level would have possibly been approximately $300 \mathrm{~m}$ lower than today. The two (Neo

\section{Sea Level Fluctuations}

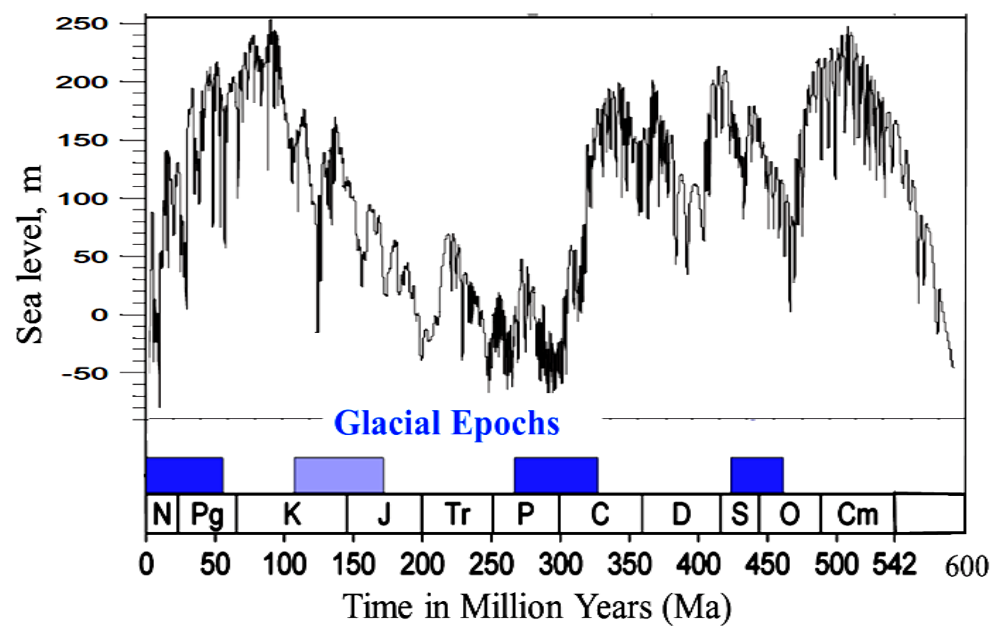

Figure 1. Exxon's sea level-curve with dominant 300 Ma cycle (after [78]). A correlation with the sea level of influencing glacial epochs doesn't seem recognizable on the first gaze [54]. 


\section{Phanerozoic Climatic Change}

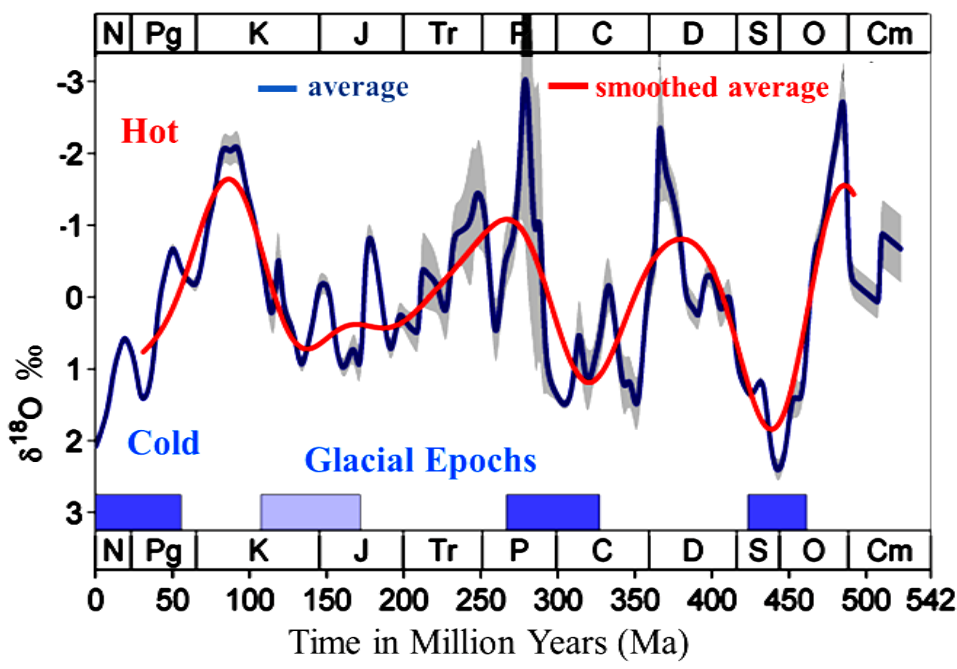

Figure 2. Climate-change in the Phanerozoic with dominant $\sim 150 \mathrm{myr}$ (million years) cycle of warm-times (greenhouse-epochs) and cold-times (glacial epochs) [58], derived from the analysis of the global distribution of oxygen-isotopes in carbonates. The relationship of the oxygen-isotopes with the mass-numbers 18 and 16 is temperature-dependent. In the evaporation-for example in the sea-water-the 16O-Isotope is preferred. The relationship of 180:16O shifts, and the 18O-Isotope becomes relatively enriched in water. In cold-times relatively much 160 becomes stored in glaciers; in the sea-water, 180 rises relatively. Plankton stores the oxygen isotope relationship of the sea surface in its carbonate framework and takes it with its death down to the seabed as temperature-information [54].

\section{Cyclic Evaporate- and Ooidsedimentation}

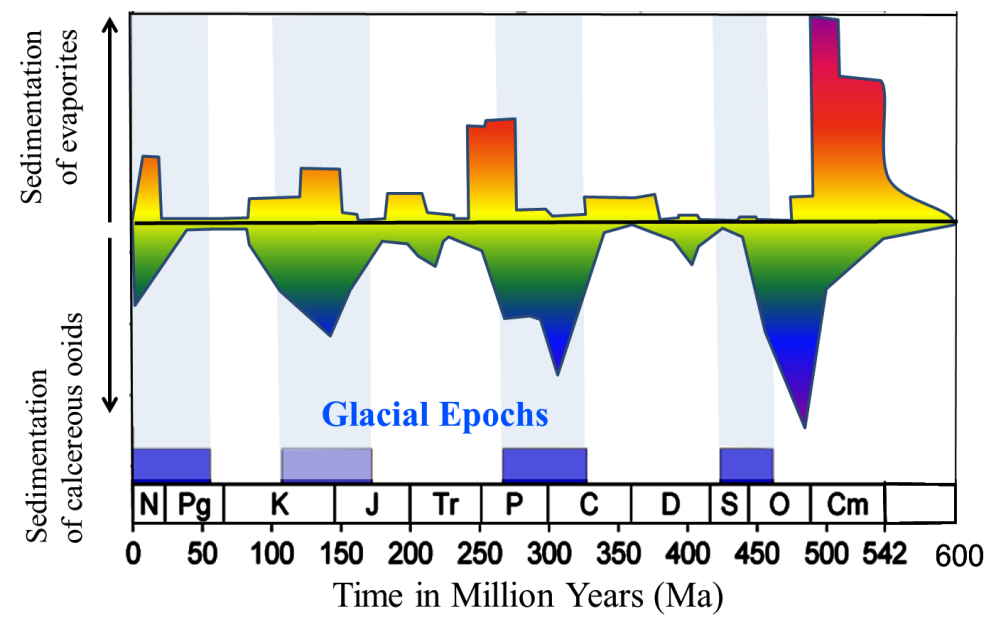

Figure 3. Sedimentation of evaporates in the Phanerozoic with $\sim 150$ myr cycle [1] [24]. Oolithic limestones show a similar distribution (scale inverted) [25]. At least, sedimentation-maxima correlate with glacial epochs for the last 400 million years [54].

proteozoic) Phanerozoic cycles, each approximately 300 million years in duration and of most different geodynamic settings, following the melting of the global "Snowball" glaciers with a noticeable time-shift, can be 
linked together to an intrinsic feedback system, in which a crucial function can be assigned to the escaping Moon due to its tidal influence on shallow seas of shelf-areas (in the geological past up to four times larger than today) and the subsequent deceleration of the Earth [36]. This must presumably include also rotation-dependent slip processes at the core-mantle-boundary of the Earth. There was initially no apparent reason to assign a cause of the cyclicity to agents outside of the Earth-Moon system. However, this may be an incorrect assumption [54].

\section{Galactic Periodicities}

As a cause of the long-periodic climate-fluctuations of approximately 150 (range: about 137 - 176) million years references [21]-[22], [55]-[58] and others have assumed cosmic influences, derived from the oxygen isotope record of shells (brachiopods, belemnites, foraminifera) that is taken as a proxy for tropical sea-surface temperatures, and partly deduced from the exposure of iron-meteorites to cosmic radiation (Figure 4).

It is remarkable that the phase-shift attributed to this periodicity is very similar to the phase-shift of the approximately 300 million year-cycle of sea level-fluctuations with overlapping minima today. Cold periods of the Earth's climate, including glaciations, correlate with fluctuations of cosmic radiation-intensity related to the cyclic path of the solar system through the spiral-arms of the Milky Way. These spiral-arms contain dense interstellar gas and dust. They are birthplaces of stars including supernovas, whose remains serve as sources of the cosmic radiation that interact with the atmosphere of the Earth. This interaction leads to a production increase of condensation nuclei, followed by enhanced cloud formation, which creates an increase of the albedo of the Earth, enhancing reflection of solar energy back into space, which is thus connected to a subsequent cooling of the Earth's atmosphere. This cooling promotes the formation of continental glaciers and therefore a significant drop in sea level with the interplay of further influences like rotation-parameters of the Earth.

With four spiral-arms of the rotating Milky Way along the orbit of the sun (Figure 5), as suspected e.g. by [59], the circular orbit around the galactic center of the somewhat faster solar system lasts approximately $4 \times$ $150=600$ million years (range: $4 \times 137=548[21]$ to $4 \times 176=704$ million years [60]). Presently, the solar system is located in a small turn-off, the Orion-Spur, between the Sagittarius-Carina and Perseus spiral-arms [57]. Since apparently two alternating spiral-arms (Scutum-Crux and Perseus arms) with a higher gas- and dustdensity exist which favors the formation of new stars and supernovas [61] and two alternating weaker ones

\section{Spiral Arm Passageways and Glacial Epochs}

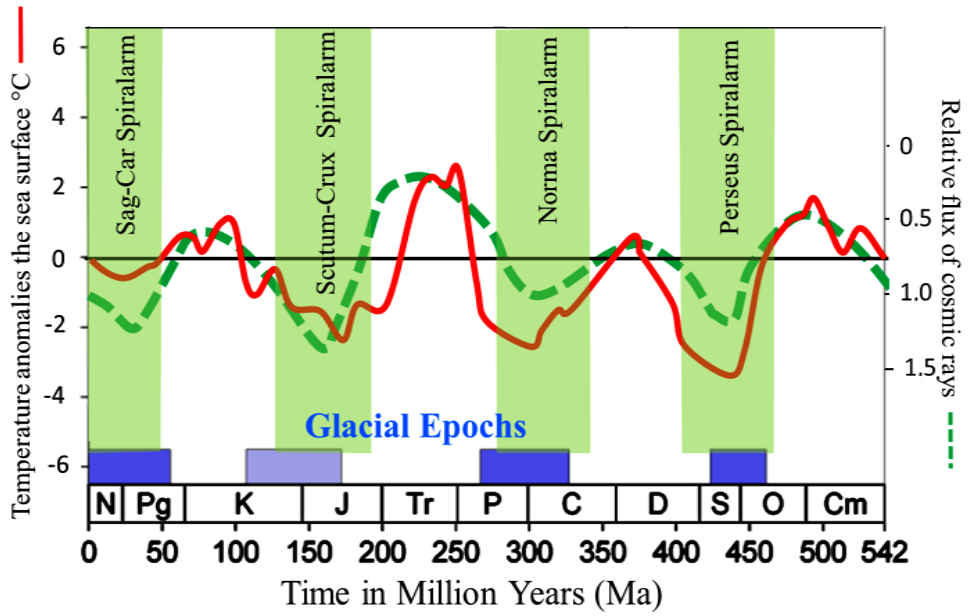

Figure 4. Phanerozoic cycles ( 150 myr) of the temperatures of the tropical sea surface (red curve) with the division of greenhouse and glacial-epochs and the flux of cosmic radiation (green shaded curve, scale inverted), that correlate with the passageways of the Earth through the spiral-arms of the Milky Way. The resulting increase in the cosmic-ray-flux enhances cloudformation by the generation of condensation nuclei. This leads subsequently to a temperature decrease. Iron meteorites are regarded as medium of the signal for the cosmic-ray-flux [21] [54]. 


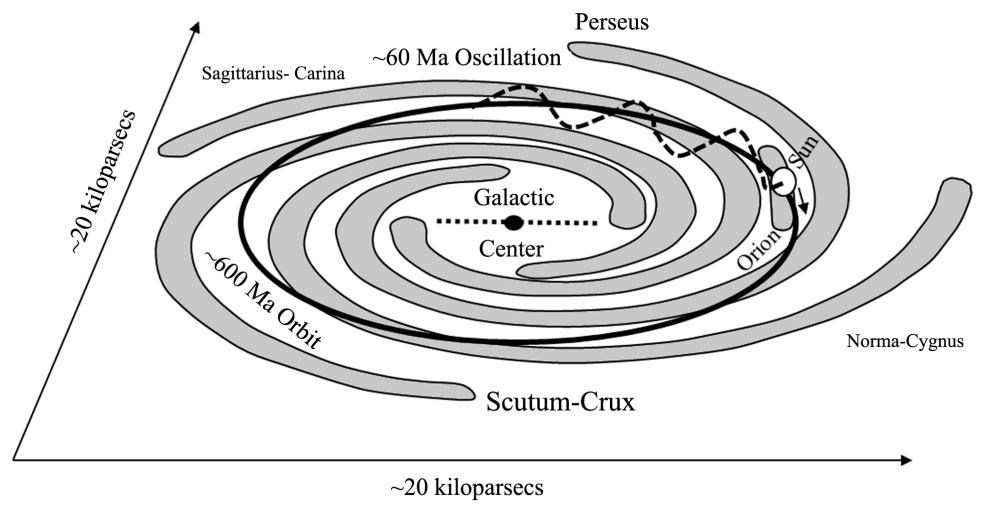

\begin{abstract}
Figure 5. A depiction of the Sun's motion relative to the spiral arm pattern modified after references [57] and [60], oscillations are not to scale. Perseus and Scutum-Crux should show a higher gas and dust-density, SagittariusCarina and Norma-Cygnus a more inferior [61].
\end{abstract}

(Norma-Cygnus and Sagittarius-Carina arms), an overlaying spectral periodicity of approximately 300 million years emerges. The relative circulation-time of approximately 600 million years is the result of the different circulation-velocities of the solar system around the galactic center and the self-rotation of the Milky Way [57] and may cause a 600 million year spectral period, but which can also be attributed to a more elliptical orbit of the solar system. In corrected times, the solar system requires approximately $200-265$ million years to orbit the galactic center. This value is dependent on how the distance between Sun and the galactic center is appraised (6.7 $9.6 \mathrm{kpc}, 1 \mathrm{kpc}$ (kilo Parsec) $\approx 3262$ light-years), and how its rotation velocity is assumed $\left(195-255 \mathrm{~km} \cdot \mathrm{s}^{-1}\right)$ [32]. Contemporarily the Sun executes oscillations with a cyclicity of approximately 60 million years which moves it out vertically from the Milky Way disk. Either it moves above the disk within the heading of the Milky Way towards the emitting galactic Virgo-cluster, or within the shadow of the Milky Way on the other side of the disk. In the first position, the solar system is the target of increased cosmic radiation due to an additional rayflux. This movement is either regarded, or vehemently disregarded, as a cause for periods of increased extinction (e.g. [32]-[34] [57] [62]).

Approximately every 600 million years, the solar system returns back to the 'same' place in the Milky Way, and approximately every 200 - 265 million years to Milky Way independent coordinates. In a rhythm of approximately $200+$ million years (apogee) the solar system gets closer to the dwarf galaxies of the Magellanic Clouds that orbit the Milky Way once every approximately 1600 million years (e.g. [63] [64]). Including the weaker influence at the perigee position within the Milky Way, an additional spectral period of 100+ Million years would occur. These Magellanic Clouds are bound by gravitational forces to the Milky Way and respond through their tidal forces by altering the shape of the Milky Way disk slightly [65].

Gravity disturbances possibly also have an influence on the path parameters of comets, asteroids and meteorites of the solar system, which can contribute to periodic frequency-maxima of cosmic impacts on the Earth and the Moon. By analyzing data from reference [66] on numbers and ages of spherules of Moon samples by a frequency-spectrum calculation, an elevated meteoritic bombardment from space took place roughly every 200 million years.

Besides possible gravitational influences through galactic rotation parameters, magnetic influences also have to be considered, since the Milky Way and its spiral-arms exhibit a complex magnetic field [67]-[69]. However, this is with strength of a few micro gauss along the solar orbit too weak in comparison to the strength of the Earth, with a value of approximately 0.5 gauss, so that a significant interaction can be negated.

The occurring periodicities in the solar system and Milky Way of approximately 600, 300, 200, 150 and 100 million years and the geodynamic cycles of the Earth show partially synchronous concurrences, which requires a detailed investigation. The assumption of random coincidence appears to be rather unlikely, however. Since the terrestrial cycles can hardly force a synchronization of the Milky Way, the question poses itself how the Milky Way can exhibit influence on the Earth. Due to their weakness, a contribution of gravity (tidal) and magnetic forces appears to be minor or unlikely. Answers can be found in the extended analysis of sea level-fluctuations 
and their dependencies to climate change if one assumes climate change as a crucial cause for long-period terrestrial cycles. For this purpose, Exxon's standardized sea level-curve ([3] [10] [11] [13] [70]-[72]) will be investigated by analyzing its spectrum accordingly. Geodynamic processes, which also influence the global sea level, include the dehydration of mountain roots due to the inevitable metamorphism, varying volumes of mid-ocean ridges combined with alternating seafloor spreading rates, episodic widespread intraplate volcanism, and deposition of marine sediments (e.g. [9] [73]-[77]). All these processes are members of the global Phanerozoic feedback system of geodynamic cycles, in which the Moon is presumably involved as an external force [36].

\section{FFT (Fast Fourier Transformation) of Exxon's Sea Level-Curve}

In the framework of an analysis of sea level-fluctuations over 15 decades of frequency (inverse of period) reference [78] examined Exxon's sea level-curve and derived a noticeable power spectrum; however, without discussing phase-shifts assigned to related amplitudes. This paper aims to discuss these amplitudes and phase-shifts, supplementing his work. Since only longer periods are of interest here, the curve with the data of the last 600 million years is reduced by an appropriate sampling rate that appears to be sufficient for the analysis of further Phanerozoic cycles as well. Since $2 \mathrm{n}$ data-points must be available for the preparation of a usual frequencyanalysis with the FFT (Fast Fourier Transformation), 64 data-points (26) can be generated by an interpolated sampling of every 9.375 million years for a period of 600 million years. Due to the Nyquist criterion that requires at least two data samples per period, the analysis terminates at a period of 20 million years. The length of the data-series of 600 million years defines the starting-period of 600 million years. The procedure determines a series of analysis-periods that were also used by reference [78] in his investigation. The length of the periods in million years follows the rule $600 / n$, here with $n=1-30$. The sequence is purely mathematically defined, however with the presetting of the geodynamic and galactic meaningful starting-period of 600 million years. All periods can be understood as approximations of the real period-spectrum. This type of analysis is admittedly questioned by reference [32] since time series-periods can appear as a result, even if they do not exist. From a practical standpoint, this uncertainty is hardly avoidable with a restricted observation time of an infinite time series [79]. In this work, a periodicity is assumed, if the amplitudes of (interacting) geodynamic processes vary over the available observation time (the last 600 million years) regularly.

The FFT was executed in MS-Excel ${ }^{\circledR}$ and the Fourier coefficients for the period-contributions of the individual sinusoidal functions were calculated. Afterwards the contributions of the individual periods, their amplitudes and phases, were investigated. To control, whether the input-curve is reconstructed again, the period contributions were summed up as a function of time under addition of the constant median value and with the necessary application of negative times (respectively negative periods). The concurrence between input-curve and output-curve was excellent. With the transformation, it became necessary to pay special attention to the calculation of the phases [80]. The analysis of Exxon's sea level-curve (for practical reasons taken from reference [78]) is shown in the following results (Figure 6):

1) Significant amplitude-contributions come from the 600, 300, 200 and 150 million year periods, where at the 300 million year period is the strongest. All periods show a range (amplitude) of approximately $100 \mathrm{~m}$. The 300 and 150 million years periods are roughly in phase. The shorter periods also are important as a sum; however, per individual case, their contribution to the total-curve is in each case below $50 \mathrm{~m}$.

2) The phases of the four large periods essentially govern the overall picture of the sea level-fluctuations. The width of the cyclic maximum between approximately 570 and 310 million years can be explained through the phase-shifted contiguous maxima of these periods.

3) A significant contribution of the 60 million year period that is related to the vertical oscillation of the solar system to both sides of the Milky Way disk has not been identified. The additional cosmic ray flux, generated by a galactic shock due to the motion of the Milky Way towards the Virgo-Cluster, did not change the climatic conditions on the Earth in the sense that detectable sea level fluctuations have occurred. However, muons produced within the shock bow have the capability to reach the Earth's surface and the bottom of the oceans and enhance the biological radiation dose [79].

\section{FFTs of Selected Geodynamic Cycles}

Similar characteristics emerge also with the analyses of plate tectonic processes like active margin magmatism and orogeny and of the history of the magnetic field of the Earth. For magmatism [18] the 300 million year pe- 


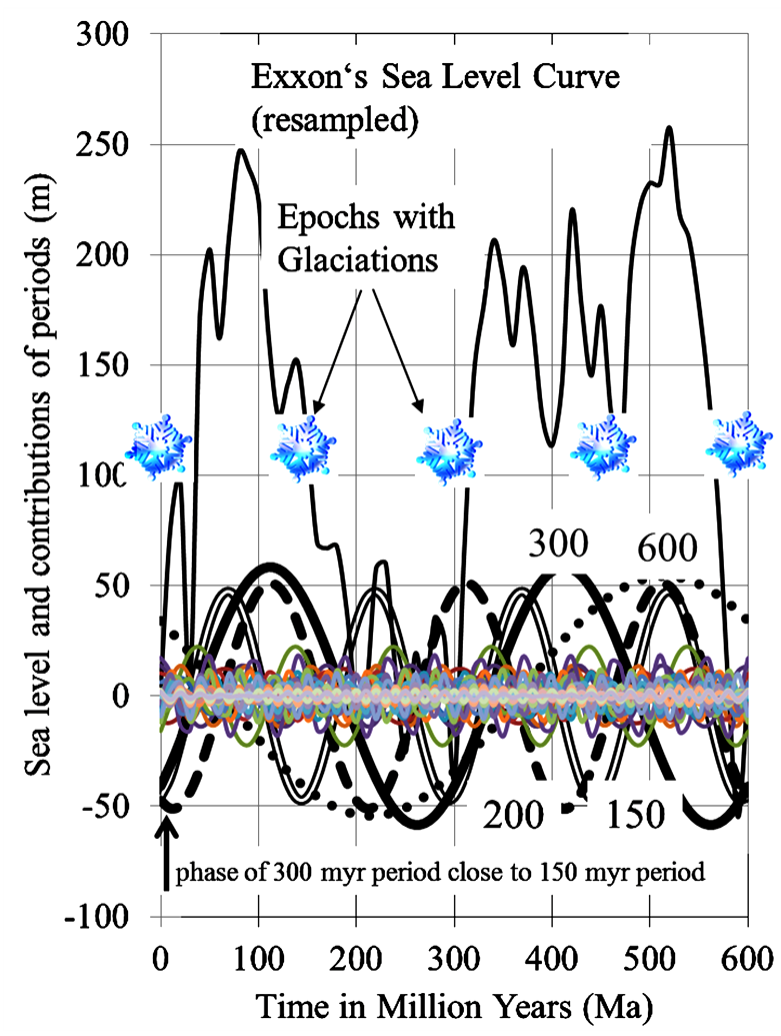

Figure 6. Analysis of Exxon's sea level curve by applying Fast Fourier Transformation (FFT), resulting in the resolution of contributing periods, their amplitudes and phases. Epochs with glaciations after references [43] and [44].

riod is significantly dominant while the contributions of the 200 and 600 million year periods are lower (Figure $7($ a)). For the orogeny [36] the 300 million year period contributes dominantly, but also the 600, 200 and 120 million years periods deliver essential contributions to the overall picture (Figure 7(b)). The historic magnetic field [16] is essentially shaped by the 600 and 300 million year periods. Of middle importance are the 200 and 100 million year periods. All other periods do not show a considerable individual contribution (Figure 7(c)).

This is also true for the galactic-climatic period of $150 \mathrm{Ma}$. Indeed, the climate does not show any significant effect on geodynamic processes of the deeper interior of the Earth. However, the climate plays a dominant role for the sedimentation of hydrocarbon source rocks directly at the surface. This can be verified through the Fourier analysis of the Phanerozoic global distribution of organic carbon after reference [8] (Figure 8). The contribution of the" "galactic" climate appears significantly recognizable in the amplitudes and phases of the 150 Ma period. During cold, galactic' epochs the contribution amplitudes of the organic carbon 150 Ma cycle are low, which points to restricted life conditions on the Earth. Glaciations of near pole areas and the extension of arid zones with the sedimentation of evaporates at lower altitudes may cause those conditions. However, just in these cold times the conditions for the sedimentation of later oil and gas source rocks may be preferable at selected places on the Earth. This becomes obvious by comparing the important intervals of source rocks after reference [28] with the result of the Fourier analysis of the organic carbon distribution after reference [8] (Figure 8). Four of the six large intervals correspond with the 150 myr (Million years) climate cycle and the remaining two with the geodynamic 300 myr cycle. In the second case the vicinity to the sea level or to the magmatic maxima appears to be so relevant that either one of them or both together govern the sedimentation process for source rocks in those times.

The concurrence between the analyzed dominant periods of the geodynamic cycles and the galactic prevalent periods is remarkable. Does this mean that a physical relationship between them exists? And if yes, what would it look like? 


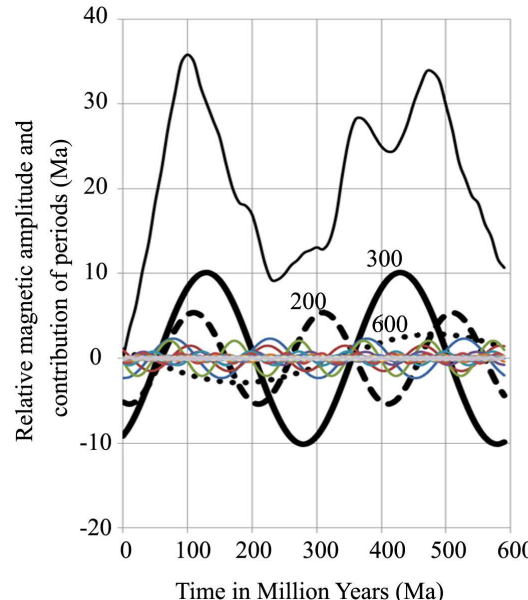

(a)

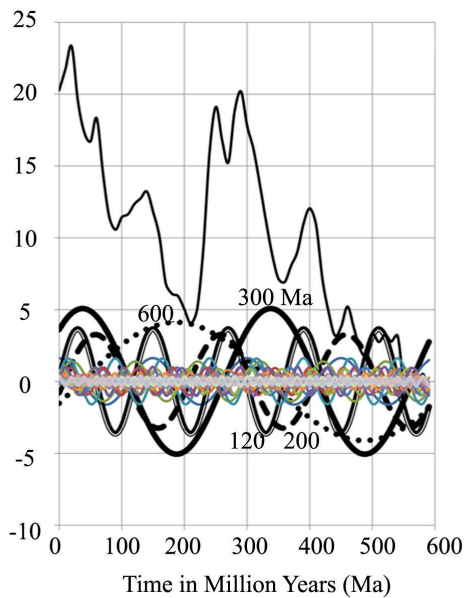

(b)

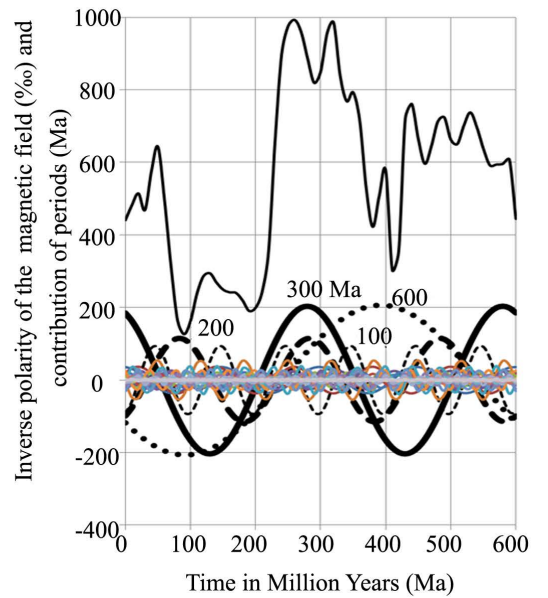

(c)

Figure 7. Geodynamic cycles and their spectral analysis [54] (a) Magmatism [18]; (b) Orogeny [36]; (c) Historical Earth's magnetic field [16].

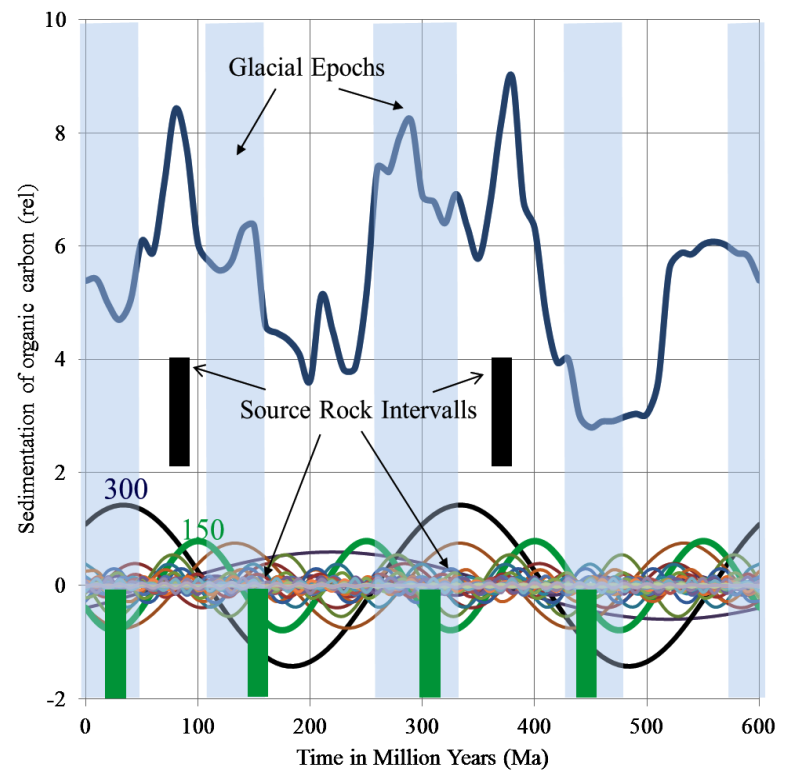

Figure 8. Fourier analysis of the sedimentation pattern of organic carbon after reference [8] and the dominant intervals for the sedimentation of petroleum source rocks after reference [28] that point to a 150 myr (climate, Milky Way; green) and a 300 myr cycle (sea level, magmatism; black) [54].

\section{Planetary Magmatic Episodes}

As shown above, a 300 myrcyclicity plays within the last $600 \mathrm{Ma}$ a dominant role in galactic episodes as well as within (synchronized?) geodynamic processes, including sea level variations, orogenic epochs, and magmatic intensities. 2400 to $600 \mathrm{Ma}$ ago a 400 myr period may have been more important as derivable from mineral ages on the Earth [19]. The Phanerozoic geodynamic processes can be seen as strongly related to forces that require the presence of oceans. However, in this sense it is certainly a surprise that volcanic activities on the ocean less Mars show intensity maxima similar to the maxima on the Earth about 100 - 200 and 400 - 800 Ma ago (Model of the Martian chronology (2008): [81]-[83]). To test whether this observation is a random coincidence, similar investigations for the other near Earth planets Venus and Mercury as well as for the Earth's Moon should be 
screened. According to reference [84], the archived geologic history of Venus is governed by an event, which let apparently to a complete melting of the crust about $10 \%-20 \%$ ago of her total age of about $4500 \mathrm{Ma}$. Since then, two magmatic maxima have been identified that appeared at relative times of about $0.1-0.15$ and 0.5 of the melting time $\mathrm{T}$. With $\mathrm{T}=900 \mathrm{Ma}$ (e.g. $20 \%$ of total age) volcanic intensity maxima have been occurred at 450 and $135 \mathrm{Ma}$ ago that lie very close to the values of Earth and Mars. Also on Mercury comparable young volcanic events have been identified which age is interpreted preliminary to be around $650 \mathrm{Ma}$ [85] [86]. Results of the newest satellite mission to Mercury that become available within the coming years may certainly verify or falsify this observation. Finally, newest results of an improved investigation of volcanic processes that happened on the Earth's Moon, lead to the assumption that the youngest events took place earlier then around $100 \mathrm{Ma}$ ago [87]. All these compiled data contain the scientific hint that an increase of magmatic/volcanic activities on the near sun terrestrial bodies may have happened synchronously around 100 and $400 \mathrm{Ma}$ ago with a time gap of the already intensively discussed period of $300 \mathrm{myr}$ (Figure 9). The cause of the increased magmatic/volcanic activity may be related to the passages of the solar system through the denser spiral arms of the Milky Way, Perseus and Scutum-Crux.

Terrestrial magmatic activities [18] and mineral ages of the Earth [19] show a significant correlation for the Phanerozoic time (Figure 9). Therefore, it appears justified to use mineral ages as indication for long term global thermal events as well (Figure 10). In pre-Phanerozoic times instead of the 300 myr cycle a 400 myrcycle may have been dominant, either as intrinsic process within the Earth or possibly as galactic process, or both. Should it be a galactic process, then following changes may have happened around 800 to 600 Ma ago:

1) The solar system was forced to move inwards to an orbit through the spiral arms about $30 \%$ closer to the center of the Milky Way by keeping its rotational speed. A more or less constant speed appears to be required taking the effect ofdark matter into account, since most stars in spiral galaxies orbit at roughly the same speedapparently in conflict with Kepler's third law ([88] and others), or

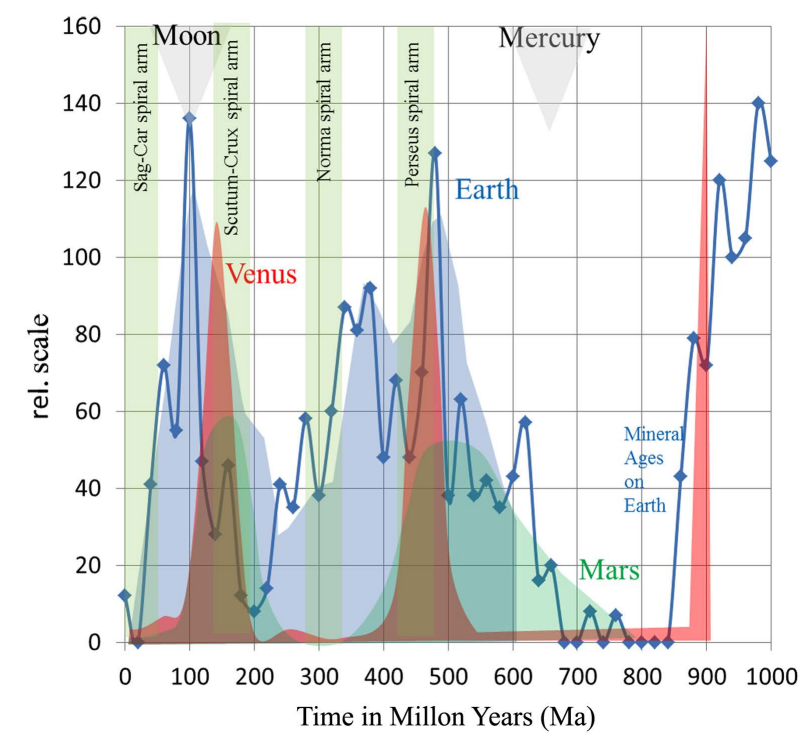

Figure 9. Compilation of magmatic/volcanic (heating) events on the Earth [18] [19], Mars (sketchy, model of the Martian chronology (2008): [81]-[83]) and Venus [84] during the Phanerozoic and Neo-Proterozoic (about the last $1000 \mathrm{Ma}$ ). It appears obviously that these planetary events are contemporaneous episodes that were accompanied by similar young magmatic activities on Mercury (possibly about $650 \mathrm{Ma}$ ago[85] [86]) and on the Earth's Moon (possibly about 100 Ma ago, [87]), pointing to an extraplanetary (galactic) cause. The cause may be related to the passages of the solar system through the denser spiral arms Perseus and Scutum-Crux of the Milky Way with a 300 myr cycle. 


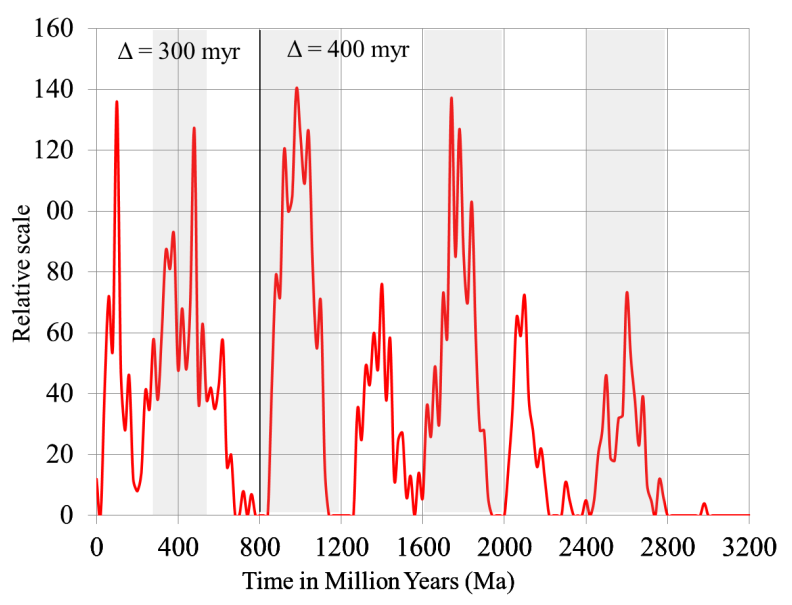

Figure 10. Mineral ages on the Earth after reference [19], showing a Phanerozoic 300 myr cycle and a preceding 400 myr cycle.

2) the solar system kept its orbit by getting forced to move faster, or

3) the rotating spiral arms were forced to slow down without affecting the rotation of the solar system or

4) a redistribution of the dark matter within the Milky Way, affecting the speed distribution of Milky Way and its stars, or

5) a combination of all, or

6) something else.

\section{Discussion}

Assuming, the approximately 150 million year cycles of climate-fluctuations on the Earth are of galactic origin, in which water is taken from the ocean in spiral-arm-controlled cold-times and subsequently deposited on the continents as ice, what would be this physical effect look like? The 150 million year cyclical-contribution of the sea level-fluctuation supports this assumption due to the similar phase between them. It is overlain by the 300 million year period with a comparable phase that results from the $2 \times 2$-spiral-arm-structure of the Milky Way. Both together cause the sea level to fluctuate by up to $200 \mathrm{~m}$. The dropping of the sea level in cold times reduces the share of the shallow-seas on the Earth and with it the tidal dissipation in shelf areas, through which the Moon influences the rotation of the Earth. This influence most likely alters the slip between the Earth's mantle and core and should consequently have an effect on the forming of the Earth's magnetic field. Interventions at the core-mantle-boundary may surely also influence the convection-cells in the mantle; however, surplus heat is transported through them from the core to the surface. Alterations of the properties of the convection-cells should influence plate tectonic processes with magmatism at active plate margins and the resulting orogeny [36]. Their cyclicity follows the sea level-fluctuations directly and therefore presumed "galactic" climate-fluctuations indirectly. The Moon acts in this sense as synchronization tool for the Milky Way, that allows the Earth to react in a common mode, and adjusts the intrinsic geodynamic processes and their phase-characteristics to the ruling galactic processes.

However, tentative contemporaneous magmatic events on all terrestrial planets including the Earth's Moon point to a ruling process outside the interior of the planetary bodies. The 300 myrcyclicity relates it presumably to properties of the rotation of the solar system around the center of the Milky Way. Heating of the planets by extraterrestrial forces and the subsequent magmatism requires processes not yet assumed. Following the discussion on dark matter and dark energy, respectively, as well as on neutrino astrophysics, a spiral arms related distribution of the dark entities or neutrino sources within the Milky Way or something else has to be assumed, should they be responsible for the observed planetary events. However, further investigations are needed to clarify any of those cosmic causes and which physical processes could have happened. Heating up the interior of the Earth by forces that do not directly affect life and geology at the surface, appears to be required. Do e.g. specific neutrinos interact with the iron inside the Earth by transferring thermal energy or are the dark entities able 
to carry it out?

\section{Conclusions}

Data regarding global sea level-fluctuations, collected predominantly by scientists of the international petroleum industry, and compiled by Exxon (see [3] and others) to form an elaborate curve, contain long-periodic signals of the Milky Way in the period-range of 600 million years and shorter. They allow us to assume that geodynamic processes on the Earth are synchronized with solar-galactic rotation-properties via climate driven sea level fluctuations, and depending on them, tidal forces of the Moon. The investigated geodynamic cycles, sea level fluctuations, orogenic periods, rhythms of magmatism at active plate boundaries and long term magnetic field variations show a dominant period of 300 million years. Contributions of 600, 200, 150 and 100 million year periodicities vary depending on the nature of the geodynamic cycle. The processes behind these cycles may act as internal physical resonators, enhancing or attenuating specific spectral periods selectively. Climate change with a period of 150 million years is assumed to be caused by the orbiting of the solar system through the spiral pattern of the rotating Milky Way, and may certainly be influenced by synchronized geodynamic cycles and their different phase shifts in turn.

Although the spiral-arm of the galaxy that possibly contributed to the Earth's "Snowball" history should have been passed through again by the solar system, the Earth was obviously saved from comparably dramatic developments and a repetition of a cosmic catastrophe. After the total freezing of the Earth in the Neoproteozoic, life developed explosively and changed almost all geodynamic and climatic boundary conditions, partly in a negative feedback by reducing an uncontrolled warm-up that became a result of periodic magmatic degasing processes due to plate tectonic processes. This includes, for example, a cyclic deposition of the greenhouse gas $\mathrm{CO}_{2}$ in thick faunal carbonate sequences at the sea bottom in warm periods, or, more generally, by floral reduction of geological erosion through the growth of land plants (e.g. [5] [8]), lending itself time enough for further evolution. A reduction of the emitting properties of the spiral arm in the meantime may have also contributed to the less dramatic situation. As magmatic episodes on the terrestrial planets of the Sun as well as on the Earth's Moon are apparently contemporaneous events, speculatively a galactic cause appears evident.

\section{Acknowledgements}

The author would like to thank anonymous reviewers for supporting this paper and Aaron Toussaint for providing language help.

\section{References}

[1] Bradley, D.C. (2011) Secular Trends in the Geologic Record and the Supercontinent Cycle. Earth-Science Reviews, 108, 16-33. http://dx.doi.org/10.1016/j.earscirev.2011.05.003

[2] Trabucho-Alexandre, J., Hay, W.W. and de Boer, P.L. (2011) Phanerozoic Black Shales and the Wilson Cycle. Solid Earth Discussions, 3, 743-768. http://dx.doi.org/10.5194/sed-3-743-2011

[3] Snedden, J.W. and Liu, C. (2010) A Compilation of Phanerozoic Sea-Level Change, Coastal Onlaps and Recommended Sequence Designations. Search and Discovery, Article ID: 40594.

[4] Bradley, D.C. (2008) Passive Margins through Earth History. Earth-Science Reviews, 91, 1-26. http://dx.doi.org/10.1016/j.earscirev.2008.08.001

[5] Berner, R.A. (1991) A Model for Atmospheric CO2 over Phanerozoic Time. American Journal of Science, 291, 339376.

[6] Tucker, M.E., Wright, V.P. and Dickson, J.A.D. (1990) Carbonate Sedimentology. Blackwell, London, 482 p. http://dx.doi.org/10.1002/9781444314175

[7] Veevers, J.J. (1990) Tectonic-Climate Supercycle in the Billion-Year Plate-Tectonics Eon: Permian Pangean Icehouse Alternates with Cretaceous Dispersed-Continents Greenhouse. Sedimentary Geology, 68, 1-16.

[8] Berner, R.A. and Canfield, D.E. (1989) A New Model for Atmospheric Oxygen over Phanerozoic Time. American Journal of Science, 289, 333-361. http://dx.doi.org/10.2475/ajs.289.4.333

[9] Tardy, Y., N'Kounkou, R. und Probst, J.L. (1989) The Global Water Cycle and Continental Erosion during Phanerozoic Time (570 my). American Journal of Science, 289, 455-483. http://dx.doi.org/10.2475/ajs.289.4.455

[10] Haq, B.U., Hardenbol, J. and Vail P.R. (1987) Chronology of Fluctuating Sea Levels Since the Triassic. Science, 235, 
1156-1167. http://dx.doi.org/10.1126/science.235.4793.1156

[11] Haq, B.U., Hardenbol, J. and Vail, P.R. (1988) Mesozoic and Cenozoic Chronostratigraphy and Cycles of Sea Level Change. In: Wilgus, C.K., et al., Eds., Sea Level Changes: An Integrated Approach, SEPM Special Publication, Houston, 71-108.

[12] Kazmierczak, J., Ittekkot, V. and Degens, E.T. (1985) Biocalcification through Time: Environmental Challenge and Cellular Response. In: Tucker, M.E., Wright, V.P. and Dickson, J.A.D., Eds., Paläontologische Zeitschrift, 59, Blackwell Scientific Publications, Hoboken, 15-33. http://dx.doi.org/10.1007/BF02985996

[13] Hallam, A. (1984) Pre-Quaternary Sea-Level Changes. Annual Review of Earth and Planetary Sciences, 12, $205-243$. http://dx.doi.org/10.1146/annurev.ea.12.050184.001225

[14] Fischer, A.G. (1982) The Two Phanerozoic Supercycles. In: Berggren, W.A. and van Couvering, J.A., Eds., Catastrophes and Earth history, Princeton University Press, Princeton, 129-150.

[15] Irving, E. and Pulliah, G. (1976) Reversals of the Geomagnetic Field, Magnetostratigraphy, and Relative Magnitude of Paleosecular Variation in the Phanerozoic. Earth-Science Reviews, 12, 35-64. http://dx.doi.org/10.1016/0012-8252(76)90053-2

[16] Creer, K.M. (1975) On a Tentative Correlation between Changes in the Geomagnetic Polarity Bias and Reversal Frequency and the Earth's Rotation through Phanerozoic Time. In: Rosenberg, G.D. and Runcorn, S.K., Eds., Growth Rhythms and the History of the Earth's Rotation, Wiley, London, 293-318.

[17] Garrels, R.M. and Mackenzie, F.T. (1971) Evolution of Sedimentary Rocks. Norton, New York, 397.

[18] Engel, A.E.J. and Engel, C.G. (1964) Continental Accretion and the Evolution of North America. In: Subramaniam, A.P. and Balakrishna, S., Eds., Advancing Frontiers in Geology and Geophysics, Indian Geophysical Union, Hyderabad, 17-37.

[19] Gastil, G. (1960) The Distribution of Mineral Dates in Time and Space. American Journal of Science, 258, 1-35. http://dx.doi.org/10.2475/ajs.258.1.1

[20] Brown, M. (2010) Geodynamic Regimes and Tectonic Settings for Metamorphism: Relationship to the Supercontinent Cycle. Indian Journal of Geology, 80, 3-21.

[21] Shaviv, N.J. and Veizer, J. (2003) Celestial Driver of Phanerozoic Climate? GSA TODAY, 13, 4-10. http://dx.doi.org/10.1130/1052-5173(2003)013<0004:CDOPC $>2.0 . C O ; 2$

[22] Shaviv, N.J. (2002) Cosmic Ray Diffusion from the Galactic Spiral Arms, Iron Meteorites, and a Possible Climatic Connection? Physical Review Letters, 89, 051102. http://dx.doi.org/10.1103/PhysRevLett.89.051102

[23] Shaviv, N.J. (2003) The Spiral Structure of the Milky Way, Cosmic Rays, and Ice Age Epochs on Earth. New Astronomy, 8, 39-77. http://dx.doi.org/10.1016/S1384-1076(02)00193-8

[24] Hay, W.W., Migdisov, A., Balukhovsky, A.N., Wold, C.N., Flögel, S. and Söding, E. (2006) Evaporites and the Salinity of the Ocean during the Phanerozoic: Implications for Climate, Ocean Circulation and Life. Palaeogeography, Palaeoclimatology, Palaeoecology, 240, 3-46. http://dx.doi.org/10.1016/j.palaeo.2006.03.044

[25] Wilkinson, B.H., Owen, R.M. and Carrol, A.R. (1985) Submarine Hydrothermal Weathering, Global Eustasy, and Carbonate Polymorphism in Phanerozoic Marine Oolites. Journal of Sedimentary Petrology, 55, 171-183.

[26] Price, G.D. (1999) The Evidence and Implications of Polar Ice during the Mesozoic. Earth-Science Reviews, 48, 183210. http://dx.doi.org/10.1016/S0012-8252(99)00048-3

[27] McAllister Rees, P., Noto, C.R., Parrish, J.M. and Parrish, J.T. (2004) Late Jurassic Climates, Vegetation, and Dinosaur Distributions. Geology, 112, 643-653. http://dx.doi.org/10.1086/424577

[28] Klemme, H.D. and Ulmishek, G.F. (1999) Effective Petroleum Source Rocks of the World: Stratigraphic Distribution and Controlling Depositional Factors. AAPG Bulletin, 75, 1809-1851.

[29] Melott, A.L., Bambach, R.K., Petersen, K.D. and McArthur, J.M. (2012) A 60-Million-Year Periodicity Is Common to Marine-87Sr/86Sr, Fossil Biodiversity, and Large-Scale Sedimentation: What Does the Periodicity Reflect? The Journal of Geology, 120, 217-226. http://dx.doi.org/10.1086/663877

[30] Halevy, I., Peters, S. and Fischer, W.W. (2012) Sulfate Burial Constraints on the Phanerozoic Sulfur Cycle. Science, 337, 331-334 http://dx.doi.org/10.1126/science.1220224

[31] Meyers, S.R. and Peters, S.E. (2011) A 56 Million Year Rhythm in North American Sedimentation during the Phanerozoic. Earth and Planetary Science Letters, 303, 174-180. http://dx.doi.org/10.1016/j.epsl.2010.12.044

[32] Bailor-Jones, C.A.L. (2009) The Evidence for and against Astronomical Impacts on Climate Change and Mass Extinctions: A Review. International Journal of Astrobiology, 8, 213-239. http://dx.doi.org/10.1017/S147355040999005X

[33] Medvedev, M.V. and Melott, A.L. (2007) Do Extragalactic Cosmic Rays Induce Cycles in Fossil Diversity? The Astrophysical Journal, 664, 879-889. http://dx.doi.org/10.1086/518757 
[34] Rohde, R.A. and Muller, R.A. (2005) Cycles in Fossil Diversity. Nature, 434, 208. http://dx.doi.org/10.1038/nature03339

[35] Walker, L.J., Wilkinson, B.H. and Ivany, L.C. (2002) Continental Drift and Phanerozoic Carbonate Accumulation in Shallow-Shelf and Deep-Marine Settings. The Journal of Geology, 110, 75-87. http://dx.doi.org/10.1086/324318

[36] Brink, H.-J. (2006) Do the Global Geodynamic Cycles of the Phanerozoic Represent a Feedback System of the Earth and Is the Moon Involved as an Acting External Force? Zeitschrift der Deutschen Gesellschaft für Geowissenschaften, 157, 17-40. http://dx.doi.org/10.1127/1860-1804/2006/0157-0317

[37] Lisiecki, L.E. and Raymo, M.E. (2005) A Pliocene-Pleistocene Stack of 57 Globally Distributed Benthic d18O Records. Paleoceanography, 20, PA1003.

[38] Hern, C., Nordlund, U., van der Zwaan, K. and Lapido, K. (2001) Forward Prediction of Aeolian Systems Using Fuzzy Logic, Constrained by Data from Recent and Ancient Analogues. Netherlands Journal of Geosciences, 80, 53-70.

[39] Strohmenger, C. and Strauss, C. (1996) Sedimentology and Palynofacies of the Zechstein 2 Carbonate (Upper Permian, NW Germany) Implication for Sequence Subdivision. Sedimentary Geology, 102, 55-77. http://dx.doi.org/10.1016/0037-0738(95)00064-X

[40] Beaufort, L. (1994) Climatic Importance of the Modulation of the 100 kyr Cycle Inferred from 16 m.y. Long Miocene Records. Paleoceanography, 9, 821-834http://dx.doi.org/10.1029/94PA02115

[41] Stothers, R.B. (1987) Beat Relationships between Orbital Periodicities in Insolation Theory. Journal of the Atmospheric Sciences, 44, 1875-1876. http://dx.doi.org/10.1175/1520-0469(1987)044<1875:BRBOPI $>2.0$.CO;2

[42] Jansen, E., Overpeck, J., Briffa, K.R., Duplessy, J.-C., Joos, F., Masson-Delmotte, V., Olago, D., Otto-Bliesner, B., Peltier, W.R., Rahmstorf, S., Ramesh, R., Raynaud, D., Rind, D., Solomina, O., Villalba, R. and Zhang, D. (2007) Palaeoclimate. In: Solomon, S., Qin, D., Manning, M., Chen, Z., Marquis, M., Averyt, K.B., Tignor, M. and Miller, H.L., Eds., Climate Change 2007: The Physical Science Basis. Contribution of Working Group I to the Fourth Assessment Report of the Intergovernmental Panel on Climate Change (IPCC), Cambridge University Press, Cambridge, 996 p.

[43] Crowell, J.C. (1999) Pre-Mesozoic Ice Ages, Their Bearing on Understanding the Climate System. Memoir Geological Society of America, 192, 1-122.

[44] Frakes, L.A., Francis, J.E. and Syktus, J.I. (1992) Climate Modes of the Phanerozoic. Cambridge University Press, Cambridge. http://dx.doi.org/10.1017/CBO9780511628948

[45] Micheels, A. and Montenari, M. (2007) A Snowball Earth versus a Slushball Earth: Results from Neoproterozoic Climate Modeling Sensitivity Experiments, Geosphere. The Geological Society of America, 4, 401-410.

[46] Hoffman, P.F. and Schrag, D.P. (2002) The Snowball Earth Hypothesis: Testing the Limits of Global Change. Terra Nova, 14, 129-155. http://dx.doi.org/10.1046/j.1365-3121.2002.00408.x

[47] Hoffman, P.F., Kaufman, A.J., Halverson, G.P. and Schrag, D.P. (1998) A Neoproterozoic Snowball Earth. Science, 281, 1342-1346. http://dx.doi.org/10.1126/science.281.5381.1342

[48] Kirschvink, J.L. (1992) Late Proterozoic Low-Latitude Glaciation: The Snowball Earth. In: Schopf, J.W. and Klein, C., Eds., the Proterozoic Biosphere, Cambridge University Press, Cambridge, 51-52.

[49] Li, Z.X., Bogdanova, S.V., Collins, A.S., Davidson, A., De Waele, B., Ernst, R.E., Fitzsimons, I.C.W., Fuck, R.A., Gladkochub. D.P., Jacobs, J., Karlstrom, K.E., Lu, S., Natapov, L.M., Pease, V., Pisarevsky, S.A., Thrane, K. and Vernikovsky, V. (2008) Assembly, Configuration, and Break-Up History of Rodinia: A Synthesis. Precambrian Research, 160, 179-210. http://dx.doi.org/10.1016/i.precamres.2007.04.021

[50] Scotese, C.R. (2004) A Continental Drift Flipbook. The Journal of Geology, 112, 729-741, and PALEOMAP Project. Department of Earth and Environ-mental Sciences, University of Texas, Arlington.

[51] Hyde, W.T., Crowley, T.J., Baum, S.K. and Peltier, W. (2000) Neoproterozoic "Snowball Earth" Simulations with a Coupled Climate/Ice-Sheet Model. Nature, 405, 425-429. http://dx.doi.org/10.1038/35013005

[52] Donnadieu, Y., Fluteau, F., Ramstein, G., Ritz, C. and Besse, J. (2003) Is There a Conflict between the Neoproterozoic Glacial Deposits and the Snowball Earth Interpretation: An Improved Understanding with Numerical Modeling. Earth and Planetary Science Letters, 208, 101-112, http://dx.doi.org/10.1016/S0012-821X(02)01152-4

[53] Tziperman, E., Abbot, D.S., Ashkenazy, Y., Gildo, H., Pollard, D., Schoof, C.G. and Schrag, D.P. (2012) Continental Constriction and Oceanic Ice-Cover Thickness in a Snowball-Earth Scenario. Journal of Geophysical Research, 117, C05016. http://dx.doi.org/10.1029/2011JC007730

[54] Brink, H.-J. (2014) [Signale der Milchstraße verborgen in der Sedimentfüllung des Zentraleuropäischen Beckensystems?]. [Signals of the Milky Way Hidden in the Sedimentary Fill of the Central European Basin System?] Zeitschrift der Deutschen Gesellschaft für Geowissenschaften, 166, 9-20.

[55] Svensmark, H. (2007) Cosmoclimatology: A New Theory Emerges. Astronomy \& Geophysics, 48, 18-24.

[56] Svensmark, H. (1998) Influence of Cosmic Rays on Earth's Climate. Physical Review Letters, 81, 5027-5030. 
http://dx.doi.org/10.1103/PhysRevLett.81.5027

[57] Gies, D.R. and Helsel, J.W. (2005) Ice Age Epochs and the Sun's Path through the Galaxy. Astrophysical Journal, 626, 844-848. http://dx.doi.org/10.1086/430250

[58] Veizer, J., Godderis, Y. and Francois, L.M. (2000) Evidence for Decoupling of Atmospheric $\mathrm{CO}_{2}$ and Global Climate during the Phanerozoic Eon. Nature, 8, 698-701. http://dx.doi.org/10.1038/35047044

[59] Englmaier, P., Pohl, M. and Bissantz, N. (2009) The Milky Way Spiral Arm Pattern. Memorie della Società Astronomica Italiana, 1, 1-6.

[60] Gillman, M. and Erenler, H. (2008) The Galactic Cycle of Extinction. International Journal of Astrobiology, 7, 17-26. http://dx.doi.org/10.1017/S1473550408004047

[61] Benjamin, R.A. (2008) The Spiral Structure of the Galaxy: Something Old, Something New. In: Beuther, H., Linz, H. and Henning, T., Eds., Massive Star Formation: Observations Confront Theory, Astronomical Society of the Pacific Conference Series, 387, Astronomical Society of the Pacific, San Francisco, 375.

[62] Feulner, G. (2011) Limits to Biodiversity Cycles from a Unified Model of Mass-Extinction Events. International Journal of Astrobiology, 10, 123-129. http://dx.doi.org/10.1017/S1473550410000455

[63] Van Der Marel, R.P., Alves, D.R., Hardy, E. and Suntzeff, N.B. (2002) New Understanding of Large Magellanic Cloud Structure, Dynamics, and Orbit from Carbon Star Kinematics. The Astronomical Journal, 124, 2639-2663.

[64] Shattow, G. and Loeb, A. (2009) Implications of Recent Measurements of the Milky Way Rotation for the Orbit of the Magellanic Cloud. Monthly Notices of the Royal Astronomical Society, 392, L21-L25. http://dx.doi.org/10.1111/j.1745-3933.2008.00573.x

[65] Williams, G.E. (1975) Possible Relation between Periodic Glaciation and the Flexure of the Galaxy. Earth and Planetary Science Letters, 26, 361-369. http://dx.doi.org/10.1016/0012-821X(75)90012-6

[66] Muller, R.A. (2002) Measurement of the Lunar Impact Record for the Past 3.5 b.y. and Implication for the Nemesis Theory. In: Koeberl, C. and MacLeod, K.G., Eds., Catastrophic Events and Mass Extinctions: Impacts and Beyond: Boulder, Colorado, 356, Geological Society of America Special Paper, New York, 659-665. http://dx.doi.org/10.1130/0-8137-2356-6.659

[67] Ruiz-Granados, B., Battaner, E., Calvo, J., Florido, E. and Rubino-Martin, J.A. (2012) Dark Matter, Magnetic Fields, and the Rotation Curve of the Milky Way. The Astrophysical Journal Letters, 755, L23. http://dx.doi.org/10.1088/2041-8205/755/2/L23

[68] Beck, R. (2009) Galactic and Extragalactic Magnetic Fields a Concise Review. Astrophysics and Space Sciences Transactions, 5, 43-47. http://dx.doi.org/10.5194/astra-5-43-2009

[69] Han, J.L. (2009) Improving Knowledge of Magnetic Fields of Our Milky Way. AAPPS Bulletin, 19, 39-41.

[70] Haq, B.U. and Shutter, S.R. (2008) A Chronology of Paleozoic Sea-Level Changes. Science, 322, 64-68. http://dx.doi.org/10.1126/science.1161648

[71] Haq, B.U. and Al-Qahtani, A.M. (2005) Phanerozoic Cycles of Sea-Level Change on the Arabian Platform. GeoArabia, 10, 127-160

[72] Hardenbol, J., Thierry, J., Farley, M.B., Jacquin, T., de Graciansky, P.C. and Vail, P. (1998) Mesozoic and Cenozoic Sequence Chronostratigraphic Framework of European Basins. In: De Graciansky, P.C., et al., Eds., Mesozoic and Cenozoic Sequence Stratigraphy of European Basins, 60, charts 1-8, SEPM Special Publication, Houston, 3-13.

[73] Schlanger, S.O., Jenkyns, H.C. and Premoli-Silva, I. (1981) Volcanism and Vertical Tectonics in the Pacific Basin Related to Global Cretaceous Transgressions. Earth and Planetary Science Letters, 52, 435-449. http://dx.doi.org/10.1016/0012-821X(81)90196-5

[74] Gurnis, M. (1990) Ridge Spreading, Subduction, and Sea Level Fluctuations. Science, 250, 970-972. http://dx.doi.org/10.1126/science.250.4983.970

[75] Kominz, M.A. (1984) Oceanic Ridge Volume and Sea-Level Change-An Error Analysis. In: Schlee, J.S., Ed., Interregional Unconformities and Hydrocarbon Accumulation, 36, American Association of Petroleum Geologists, Tulsa, 109-127.

[76] Harrison, C.G.A., Brass, G.W., Saltzman, E., Sloan, J., Southam, H.J. and Whitman, J.M. (1981) Sea Level Variations, Global Sedimentation Rates and the Hypsographic Curve. Earth and Planetary Science Letters, 54, 1-16. http://dx.doi.org/10.1016/0012-821X(81)90064-9

[77] Pitman III, W.C. (1978) Relationship between Eustacy and Stratigraphic Sequences of Passive Margins. Geological Society of America Bulletin, 89, 1389-1403. http://dx.doi.org/10.1130/0016-7606(1978)89<1389:RBEASS $>2.0 . C O ; 2$

[78] Harrison, C.G.A. (2002) Power Spectrum of Sea Level Change over Fifteen Decades of Frequency. Geochemistry Geophysics Geosystems, 3, 1-17. 
[79] Atri, D. and Melott, A.L. (2011) Biological Implications of High-Energy Cosmic Ray Induced Muon Flux in the Extragalactic Shock Model. Geochemistry Geophysics Geosystems, 38, L19807.

[80] Oliveira, M., Nápoles, S. and Oliveira, S. (2012) Fourier Analysis: Graphical Animation and Analysis of Experimental Data with Excel. Spreadsheets in Education (eJSiE), 5, 18 p. http://epublications.bond.edu.au/ejsie/vol5/iss $2 / 2$

[81] Hartmann, W.K. and Neukum, G. (2001) Cratering Chronology and the Evolution of Mars. Space Science Reviews, 96, 165-194. http://dx.doi.org/10.1023/A:1011945222010

[82] Werner, S.C. (2009) The Global Martian Volcanic Evolutionary History. Icarus, 20, 44-68. http://dx.doi.org/10.1016/j.icarus.2008.12.019

[83] Robbins, S. J., Di Achille, G. and Hynek, B. M. (2011) The Volcanic History of Mars: High-Resolution Crater-Based Studies of the Calderas of 20 Volcanoes, Icarus, 211, 1179-1203. http://dx.doi.org/10.1016/j.icarus.2010.11.012

[84] Basilevsky, A.T. and Head, J.W. (2002) Venus: Analysis of the Degree of Impact Crater Deposit Degradation and Assessment of Its Use for Dating Geological Units and Features. Journal of Geophysical Research, 107, 5-38. http://dx.doi.org/10.1029/2001JE001584

[85] Thomas, R.J., Rothery, D.A., Conway, S.J. and Anand, M. (2014) Long-Lived Explosive Volcanism on Mercury. Geophysical Research Letters, 41, 6084-6092. http://dx.doi.org/10.1002/2014GL061224

[86] Thomas, R. J., Rothery, D.A., Conway, S.J. and Anand, M. (2015) The Timing and Distribution of Pyroclastic Volcanism on Mercury. Dept of Physical Sciences, the Open University, Milton Keynes.

[87] Braden, S.E., Stopar, J.D., Robinson, M.S., Lawrence, S.J., van der Bogert, C.H. and Hiesinger, H. (2014) Evidence for Basaltic Volcanism on the Moon within the Past 100 Million Years. Nature Geoscience, 7, 787-791. http://dx.doi.org/10.1038/ngeo2252

[88] Koupelis, T. and Kuhn, K. F. (2007) In Quest of the Universe. Jones \& Bartlett Publishers, Sudbury, 492. 